\title{
Oskar Kolberg o Rusinach/Ukraińcach i ich kulturze
}

\section{Abstract \\ Oskar Kolberg about Rusyns/Ukrainians and their Culture}

The article informs about ethnographic materials regarding the culture of Rusyns/Ukrainians in the works of Oskar Kolberg, a documentalist of this culture in the 19th century. It shows what these materials are, where they come from, how they were collected and how they were made available. The author also presents Kolberg's knowledge and beliefs about the Rusyns. He also discusses the reception of Kolberg's work in past and modern Ukrainian and Polish science. The author is convinced that ethnographic materials from the 19th century collected by Kolberg are important cognitively and have the ability to shape the identity of people living today.

Keywords: Kolberg, Rusyns, folk culture, interethnic relationships, Ukrainian ethnology, Polish ethnology.

W niniejszym opracowaniu będę starał się odpowiedzieć na trzy, jak mi się wydaje ważne, ale jednak nieobejmujące wszystkich spraw zasygnalizowanych w tytule, pytania: skąd, jaki i w jaki sposób Oskar Kolberg zgromadził materiał etnograficzny dotyczący Rusinów/Ukraińców?; kim byli Rusini dla Oskara Kolberga i jakie były i są recepcja oraz pożytek z „rusińskich” materiałów Kolbergowskich w nauce i społeczeństwie ukraińskim i polskim? 


\section{Materiał etnograficzny dotyczący Rusinów/Ukraińców w dziełach Kolberga}

Określenie lokalizacji materiałów to jedna z mocnych stron dokumentacji gromadzonej przez Oskara Kolberga. Oczywiście w tak licznych zapisach zdarzają się pomyłki i zaniedbania. Na teren, z którego pochodzą dane, wskazują tytuły tomów nazywanych przez nas monografiami regionalnymi i suplementami do nich. Ziemiom zamieszkanym przez Rusinów/Ukraińców poświęcił Kolberg wydane przez siebie cztery tomy Pokucia (1882-1880) oraz jeden tom Chełmskiego (1890). Niedługo po śmierci Kolberga z jego materiałów opublikowano Chełmskie, cz. 2 (1891), Przemyskie (1891) i Wołyń (1907). Najliczniejsze są tomy monografii regionalnych i suplementy do monografii już ogłoszonych przygotowane z rękopisów przez Redakcję Dzieł Wszystkich Oskara Kolberga, przekształconą w Instytut im. Oskara Kolberga. Są to: Ruś Karpacka, dwa tomy (1970-1971); Sanockie-Krośnieńskie, trzy tomy (1973-1974); Ruś Czerwona, dwa tomy (1976-1979); Podole (1994) oraz tomy Wolyń. Suplement (2002); Chetmskie. Suplement (2004); Pokucie. Suplement (2008); Przemyskie. Suplement (2011), a także przygotowane już do druku Materiały do etnografi Słowian wschodnich. W sumie 21 tomów „Dzieł wszystkich" (niektóre z nich w kilku częściach) spośród 68 tomów monografii regionalnych i suplementów do nich, największy zbiór materiałów do kultury ukraińskiej zebrany w XIX wieku przez jednego człowieka, stanowiący także znaczną część ogólnej spuścizny badacza. Kolberg cenił te materiały; o Pokuciu napisał, że będzie najbardziej dokładną z dotychczasowych monografii (Kolberg 1966: 427). Materiały dotyczące Rusinów zbierał przede wszystkim z trzech powodów: zamierzał przedstawić opis ludu z całego obszaru dawnej Rzeczypospolitej; interesował się Słowiańszczyzną oraz był przekonany o bogactwie jej kultury ludowej i znaczeniu jej dokumentacji dla nauki.

$\mathrm{W}$ materiale dominują, biorąc pod uwagę ich związek z kulturą, pieśni, w większości zapisane wraz z ich melodiami, co było niezwykle rzadkie w tym czasie. Ważne są również zapisy prozy ludowej („kazki”, legendy, bajki, przysłowia), a także nazwiska, zawołania na zwierzęta, przyczynki słownikowe, obszerne i liczne opisy zwyczajów i obrzędów, szczególnie wesela, ogólne wiadomości o ludzie i o kraju oraz wiele innych. Uwzględniając sposób uzyskania materiałów, można wyróżnić własne zapisy Kolberga z wywiadów, a także sporządzone przez niego opisy, należące do kategorii źródeł wywołanych. Najcenniejsze wśród nich, bo wyjęte jak gdyby z badanej kultury, są zapisy terenowe pieśni i melodii, porównywalne z obiektami materialnymi z odległych epok, najbardziej obiektywne, ale i niepozbawione ingerencji badacza. Inne cechy mają sporządzone w terenie wymienione już opisy, nie tylko obrzędów, tak częste u Kolberga, lecz także między innymi ubiorów odróżniających grupy ludzi i innych rzeczy, obiektów dostarczonych na Wystawę Etnograficzną w Kołomyi w roku 1880. Wystawa ta, któ- 
rej „Układ wewnętrzny... przypadł w udziale zaszczytnie znanemu etnografowi p. Oskarowi Kolbergowi..." (Turkawski 1880: 2), przez współczesnych nam ukraińskich etnografów została uznana za ważną, gdyż przekonywała o talencie twórców ludowych, dostarczyła źródeł do napisania wielu prac etnograficznych i dała podstawy dla stworzenia przyszłego Muzeum w Kołomyi (Zbyr 2014: 87). Kolberg posługiwał się ponadto źródłami zastanymi: zapisami terenowymi innych osób, wypisami z literatury, wykorzystanymi in extenso lub w streszczeniach, notatkami z dokumentów osobistych i urzędowych, a nawet wycinkami prasowymi. Krytyka źródeł zastanych pojawia się rzadko, i to najczęściej w przypisach, a także w postaci znaków zapytania i wykrzykników. Kolberg tłumaczył, że jest zbieraczem, krytykę pozostawia badaczom z poszczególnych dyscyplin naukowych.

Badania terenowe na ziemiach zamieszkałych przez Rusinów/Ukraińców Kolberg prowadził od roku 1859 (Chełmskie), głównie na dworach polskiej szlachty, które nazywał stacjami naukowymi, gościł także w plebani księdza greckokatolickiego, nie wędrował po nich $\mathrm{z}$ kosturem w ręku, jak to w młodości niekiedy czynił na obszarze etnicznie polskim. Na początku swych badań „nie znał języka ruskiego tak, aby mógł zrozumieć wszystko, co przy zapisywaniu słów do uszu jego dochodziło" (Tretiak 1964, 1907: IX). Tłumaczył się z tej nieznajomości również później i prosił o pomoc, choć osłuchany był już z językiem. Rozmawiał z ludźmi sprowadzonymi do dworu lub, jako gość dworu, szedł na wieś. $Z$ tą metodą prowadzenia badań wiąże się szczególny sposób doboru przekazywanych treści, podlegających wielostopniowej cenzurze: społecznej, mieszkańca wsi rozmawiającego z człowiekiem z miasta, gościem dworu, odczuwającego też kontrolę własnej społeczności oraz etniczno-religijnej - Rusina komunikującego się z przedstawicielem polskiej grupy etnicznej, odrębnej także wyznaniowo. Prowadząc badania terenowe, Kolberg korzystał jednak również z pomocy Rusinów jako swoich przewodników i gromadzących dla niego materiały. Należeli do nich na Pokuciu i Huculszczyźnie ks. Sofron Witwicki z Żabiego, Bazyli Jurczeńko, pochodzący z Ispasu i nauczyciel w tejże wsi, później student prawa w Czerniowcach, Iwan Nikityszyn i Iwan Czermak (Skrukwa 2008: X i n.). To dzięki ich pomocy, a także umiejętności nawiązywania kontaktów z rozmówcami i uczciwości badawczej, w zbiorach znalazły się teksty trudno dostępne dla obcych. Należą do nich pieśni wyrażające poczucie krzywdy doznanej od Polaków-Lachów i niechęć wobec nich. Taka jest pieśń powstała po zniesieniu pańszczyzny w roku 1848:

Piszly pany do cisary

A wzieli prosyty:

pozwol, pozwol cisarońku

pańszczynu robyty.

Ne pozwolu, wrahy Lachy,

Bo wy wrażdujete,

bidny mużyk narobyt si 
a wy zbytkujete

(Kolberg 1963, 1883: 244) ${ }^{1}$.

Pieśń tę, zapisaną najprawdopodobniej w Czortowcu, wsi należącej do Władysława Przybysławskiego, jednego z najlepszych swoich współpracowników, Kolberg zaopatrzył w przypis wyjaśniający, że w rocznicę darowania pańszczyzny odprawiane jest między 3 a 15 maja w cerkwiach specjalne nabożeństwo. Podobnych pieśni jest wiele, na przykład ta ze strofą:

Oj, wijt wstaje rano, kryczyt pid okoncem,

A szczob wyjty na panszczynu pered schodom soncem...

Kob ny tyi wraży Lachy buwby mużyk panem,

czerez tyje wraży Lachy zostaje gałganem

(Kolberg 2002: 232).

Pieśni wyrażają także treści ambiwalentne: „Laszki zdradliwyi lude...” i „Laszki syt myrnyi lude" (Kolberg 1976: 827, 850). Podkreślają związek z regionem i grupą regionalną: my Huculi, Bojkowie, Łemkowie, Podolanie; poświadczają także, choć rzadziej, świadomość szerszej wspólnoty etnicznej:

Kuda hlanu, Boże moj,

wsiuda Rusyn, wsiuda swój.

Mołodec to, czy diwa,

w kożdim, w kożdim krou żywa

(Kolberg 1972: 290).

Materiały ujawniają stosunek nie tylko do Lachów oraz tak zwanych Mazurów, polskiej, głównie chłopskiej ludności żyjącej wśród Rusinów, inaczej przez nich traktowanej i najczęściej rutenizującej się. Przynoszą wiadomości także o Żydach. Rozmowa $\mathrm{w}$ chacie jednego $\mathrm{z}$ nielicznych informatorów wymienionych $\mathrm{z}$ nazwiska, Skirczuka z Żabiego, w obecności wprowadzającego go do niej greckokatolickiego księdza Sofrona Witwickiego, zaliczanego do grupy „Gente Rutheni, natione Poloni” (Świątek 2014: 307-308), dostarczyła „kazkę” o konieczności wygnania Żydów z ziemi ruskiej (Kolberg 1962, 1889: 286). Kolberg ponadto zgromadził kilkanaście wersji pieśni „Jide, jide Dzelman” i gry w Zelmana. Według interpretacji zawartej w "gadce” opowiadanej w okolicy Hrubieszowa i Horodła pieśń ta była oparta na wydarzeniu historycznym, którym miało być dzierżawienie cerkwi przez Żydów (Kolberg 1964, 1890: 137). Historycy, między innymi Mychajło Hruszewśkyj w swojej Istoriji Ukrajiny-Rusi (Gruševs'kij 1922: 126), zaprzeczają możliwości oddawania cerkwi w dzierżawę (jak to robiono $\mathrm{z}$ karczmami), a wiadomość o tym traktują jako hasło agitacyjne, docenione i upowszechnione między innymi przez Mikołaja Gogola w Tarasie Bulbie (2002: 47-48). Interesujące są współczesna recepcja i funkcje tej pieśni, znanej zarówno Ukraińcom, jak i Pola-

1 Przy powtórzonych wydaniach prac Kolberga odnotowuję, w drugiej kolejności, rok ich pierwszej publikacji, ważny dla umieszczenia tych prac w biografii badacza i w dziejach nauki. 
kom. Wśród Ukraińców nadal pozostaje znakiem spraw z przeszłości służącym między innymi postrzeganiu przedstawicieli innych grup etnicznych, natomiast wśród Polaków utraciła walor świadectwa historycznego oraz konotacje etniczne i wykorzystywana jest w zabawie (Jasiewicz 2017).

Ważne są również inne utrwalone przez Kolberga materiały dotyczące spraw etnicznych. Należą do nich pieśni mówiące o miłości młodych z różnych grup etnicznych, często kończącej się małżeństwem. Wiadomo, że małżeństwa mieszane są istotnym wskaźnikiem stosunków i procesów interetnicznych. Pieśń od Kowla opowiada:

Sino sobi hromadyła,

i Laszeńka prynadyła...

bo to Laszok charoszy...

o to Laszok moja dusza

(Kolberg 1964, 1907: 206).

Inna pieśń z Barysza:

Komuz ja się, mołodeńka, pogistanu²,

cy diakowy, cy Lachowy - sudy Boże.

Jak diakowy i Lachowy - sudy Boże,

Jak jakomu pyjakowy - ne daj Boże

(Kolberg 1978: 181-182).

Związki mieszane etnicznie stwarzały trudności. Matka strofuje, a dziewczyna się żali:

Ty diwczyno, szczo ty robysz,

soromu ne majesz,

czom kozakiw, a ne Lachiw,

wirne ne kochajesz?

A szczoż toje łycho robyt

stareńkaja maty,

hnała mene wid Laszońka

do samoji chaty;

A u Lacha werszok nyzkij,

szeroki obuszki,

skorom Lacha zobaczyła

prystaw me do duszki

(Kolberg 1979: 909).

W Sandomierskiem śpiewano: „Niewola mnie przymusiła, co ja wyszła za Rusina" (Kolberg 1962, 1865: 39).

2 W tekście pieśni nad literką „g” nadpisane małe „d”. 
Asymilacja etniczna dokonywała się także przez zmianę stanu, a ta wymagała odpowiedniego ubioru. Scena z targu: Żyd sprzedający chłopu kożuch stroi w niego kupującego i woła: „A hdeż Jwan? Wże ny ma Jwana, ny ma, ny ma, ale no, a tylko je pan Jan, pan Jan! Ca ca ca ca!" (Kolberg 1976: 57).

Ważna była rola cerkwi w utrzymywaniu odrębności etnicznej i budzeniu poczucia wspólnoty. Kozak, który nie zna pana, był w pieśni nie tylko idealnym kochankiem. Stanowił symbol wolności, młodości, waleczności, mobilności, tak atrakcyjny dla pańszczyźnianego chłopa, również później przywiązanego do ziemi i wioski:

Toj szczasływy, kto zrodywsia

Na pustyni Kozakom...

(Kolberg 1968: 394).

Był także inny kozak, na służbie pańskiej, często znienawidzony. Dozorujący roboty w polu nosił nazwę atamana. Trwał mit Ukrainy, istotny w rodzącej się ideologii narodowej:

\footnotetext{
Na Ukraini wsioho mnoho

I paszy, i brahy,

łesze szo tam Lachy stojat,

kozaćkiji wrahy;

Na Ukraini wsioho mnogo,

medu i horiwki,

diwki krasni, mołodyci,

a wsi czarnonobrywki;

(Kolberg 1979: 908).
}

Materiał folklorystyczny, pieśni, prozę, traktuję jako nie tylko źródło wiedzy o nich samych, o literaturze ludowej. Po uwzględnieniu jego specyfiki: szczególny język i poetyka, związane z nią posługiwanie się symbolami, a także swoiste stosowanie kategorii czasu, częste jej unieważnianie, można za pomocą tego materiału dotrzeć do niektórych sfer spoza folklorystycznej rzeczywistości ludzi, których jest własnością: światopoglądu i w jego ramach systemu wartości, w tym oceny stosunków społecznych i etnicznych, miejsca wierzeń, związanych z nimi zachowań, poglądów na przeszłość i wyobrażeń o przyszłości, a nawet zespołu przedmiotów występujących zwykle w roli symboli. Przy jego interpretacji jako nośnika wiedzy o rzeczywistości szerszej niż stanowiąca folklor konieczne jest jednakże korzystanie również z innych kategorii źródeł. 


\section{Status społeczno-kulturowy i etniczny Rusinów w poglądach Kolberga}

Kolberg znał specyfikę społeczną Rusinów. Z artykułu Rusini i ich język, zamieszczonego w roku 1836 w „Przyjacielu Ludu”, który streścił, wiedział, że język „ruski” przestał być „księgowym”, a „Rusini istnieją w jednej tylko klasie ludzi, to jest w wiejskich mieszkańcach" (Kolberg 1976: 20). Traktował Rusinów jako masę etnograficzną, o którą walczą Polacy i Rosjanie, nie uwzględniał zmian dokonujących się w strukturze społecznej grupy w czasie jego życia. Szanował natomiast ludzi i ich kulturę. Napisane z irytacją i opublikowane w roku 1890 słowa w odpowiedzi na recenzję Iwana Franki tomu III Pokucia:

Wprawdzie można jeszcze było [...] pod każdą śpiewką - jakby tego recenzent zapewne pragnął - podać dla potomności i nazwiska śpiewaków Hryciów lub śpiewaczek Hafek, co by w mniemaniu jego znakomicie użyteczność zbioru podniosło, lecz - przyznajmy się do tego otwarcie - uczynić tego nie uważaliśmy już za rzecz konieczną, więc zaniedbaliśmy tych szczegółów, równie jak i nasi poprzednicy (Kolberg 1971: 414, 2008: 289).

nie oznaczały lekceważenia Rusinów - informatorów. Wyrażały głębokie przekonanie Kolberga, że twórczość ludowa jest dziełem zbiorowym. W podobny sposób mógł napisać, moim zdaniem, rejestrując materiał z ziem etnicznie polskich, o śpiewakach Jasiach i śpiewaczkach Kaśkach.

Rusini byli dla Kolberga ludnością wiejską południowo-wschodnich terenów dawnej Rzeczypospolitej, odrębną etnicznie. Nie ma racji Joanna Tokarska-Bakir (2004), która stwierdziła, że Kolberg uważał na przykład Hucułów i Bojków za „lud polski”. Rusinów niekiedy określał jako „lud nasz”, nigdy natomiast jako lud etnicznie polski. Nie negując odrębności etnicznej Rusinów, którą pragnął udokumentować, jednocześnie postrzegał ich jako zespół etnograficznych grup regionalnych, nie chciał w nich dostrzec potencjału narodowotwórczego, mimo że o zapoczątkowanym procesie integracji tych grup dowiadywał się także z lektur. Przetłumaczył między innymi artykuł J.D. Wahylewycza z roku 1938 na temat Hucułów, z zawartym w nim stwierdzeniem: „Hucułowie już teraz przetopili się w narodowość ruską i pod względem rozwoju duszewnego są, oprócz pewnej dzikości i szorstkości, powtarzającym się obrazem tego samego życia ruskiego..." (Kolberg 1970: 33).

Kolberg, choć stykał się z inteligencją rusińską działającą w Galicji Wschodniej, nie zamierzał jej wspierać $w$ działaniach zmierzających do podkreślenia odrębności w stosunku do Polaków. Traktował ją jako sprzyjającą Rosjanom. Nie pragnął, aby jego „dzieło wyszło po rusku i ruskimi było drukowane czcionkami”, bo to, jak pisał: „Z moimi nie zgadzało się przekonaniami” (Kolberg 1966: 687). Czerpał satysfakcję z tego, że cesarz Franciszek Józef, po dłuższym zwiedzaniu wystawy etnograficznej w Kołomyi w roku 1880, której współorganizatorem był Kolberg, „odjechał na wystawę Kaczkowskiego (ruską), gdzie parę minut tylko 
zabawił" (Kolberg 1966: 409). Jednocześnie potrafił on docenić poszczególnych Rusinów, nie reagował na przykład na ostrzeżenie Władysława Przybysławskiego informującego Kolberga, że dostarczający mu materiały Bazyli Jurczeńko „stanowczo przeszedł do obozu Świętojurców, a właściwie do Moskali” (Kolberg 1969: 575), i nadal z nim korespondował i wysyłał w podziękowaniu swoje prace.

Zmiany w poglądach Kolberga na Rusinów pojawiły się pod koniec jego życia w wyniku korespondencji, w roku 1884, z Czesławem Neymannem, adwokatem kijowskim, wspartym uznawanym przez Izydora Kopernickiego autorytetem. Neymann ostro zareagował na zawarte w skierowanym do niego liście Kolberga (2008: 269) umieszczenie Rusinów w podziale na Ruś Południową i Północną. Napisał:

Szanowny Pan mówi: „pod całą Ruś południową rozumiem właśnie halicką, chełmską, Wołyń, Podole, Ukrainę i Małorosję, do północnej zaś zaliczam Białoruś z częścią Polesia i Wielkorosję". W takim określeniu tkwi i omyłka etnograficzna, i dla Rusinów obraza. Rusin bardzo się obraża, gdy go za południowego Moskala mają. Grupa wielkorosyjska ma swoje narzecza i podnarzecza, a grupa rusińska swoje (Kolberg 2008: 271).

Kolberg tłumaczył się, dlaczego gotów był traktować Rusinów, zarówno tych z południa, jak i północy, łącznie, sprowadzając rzecz do spraw językoznawczych:

Za wyjaśnienie dotyczące podziału języków słowiańskich na grupy i stosunku wzajemnego różnych narzeczy i gwar między sobą wielce jestem zobowiązany, tym bardziej, że popiera zdanie Pańskie w zupełności dr Kopernicki. Ja zaś, wychowaniec dawnej szkoły, nie lingwista z powołania, czerpiący swą naukę z poglądów jeszcze Szafarzyka, który dzielił całą Słowiańszczyznę na dwie połowy, tj. zachodnią i wschodnio-południową (i do tej ostatniej zaliczał Moskwę, całą Ruś, Serbię itd.), nie miałem dotąd jasnego o całości wyobrażenia, badając etnograficznie jedynie Ruś nam najbliższą (Kolberg 2008: 273).

Nie wiemy jednakże, czy potwierdzenie odrębności Rusinów od Rosjan oznaczało jednocześnie uznanie ich jednorodności i praw narodowych. Sądzić należy, że Kolberg trzymał się poglądów ukształtowanych już w młodości, przekazywanych chociażby przez Wacława Zaleskiego, przyjmujących włączenie Rusinów, tych z ziem dawnej Rzeczypospolitej, do narodu polskiego. Determinacja w dokumentacji kultury Rusinów i brak wiary w ich potencjał w zakresie tworzenia narodu świadczą o często skomplikowanej relacji między osobowością i przekonaniami badacza a charakterem i skutkami jego prac.

\section{„Rusińskie" materiały Kolberga w nauce i społeczeństwie ukraińskim i polskim}

Materiały Kolbergowskie dokumentują folklor i inne dziedziny kultury ukraińskiej z drugiej połowy XIX wieku poprzez badania terenowe, zawierają także zapisy muzyczne, wyjątkowe w tym czasie. Dostarczają również źródeł do studiów 
nad folklorem i do studiów etnologiczno-historycznych w celu rekonstrukcji kultury wsi ukraińskiej wymienionego okresu. Są poza tym uznawane za utrwalające ważną część dziedzictwa narodowego, szczególnie cenionego w narodzie w przeszłości nieposiadającym silnych i ustabilizowanych elit kulturalnych (prezydent Juszczenko ceniony był jako kolekcjoner dzieł sztuki ludowej).

Materiały te stanowią inspirację dla działalności artystycznej i wskazują na międzynarodowy charakter nauki, na więzi między nauką polską a ukraińską. Stwarzają możliwości badań porównawczych w ramach kultury ukraińskiej, słowiańskiej i europejskiej.

O zainteresowaniu w nauce ukraińskiej dziełami Kolberga, jeszcze za jego życia, świadczy recenzja Pokucia napisana przez Iwana Frankę, badacza niezwykle zasłużonego dla rozwoju etnografii nie tylko ukraińskiej, ale także polskiej. Wykorzystywał on materiały Kolbergowskie w wielu swoich pracach, również polecał je innym badaczom ukraińskim. Zdecydowanie krytycznie odniósł się do recenzji dwóch pierwszych tomów Pokucia, napisanej przez Iwana Kołessę, broniąc Kolberga przed zarzutem plagiatu nie tylko ze zbioru pieśni Jakiwa Hołowackiego, ale także Wacława Zaleskiego i Żegoty Paulego (Zbyr 2014: 194). O pozytywnej ocenie prac i postaci Kolberga przez Frankę świadczy ponadto, przypomnijmy, podpis tego ostatniego pod adresem skierowanym w roku 1889 przez Redakcję „Kuriera Lwowskiego" do polskiego badacza z okazji 50-lecia jego pracy naukowej: „Niestrudzonemu autorowi $L u d u$, badaczowi, który światłem przelanym na stosunki i ducha ludu zadanie demokracji polskiej i ruskiej znakomicie ułatwił..." (Kolberg 1969: 591). Mamy jeszcze inne informacje o pozytywnych opiniach o dziele Kolberga uczonych ukraińskich, współczesnych temu badaczowi i późniejszych, oraz jego recepcji w ich pracach (Mykoły Sumcowa, Wołodymyra Hnatiuka, Filareta Kołessy, Iwana Kołessy, Wołodymyra Szuchewicza), a także o zainteresowaniu tym dziełem również współczesnych nam etnologów i folklorystów (m.in. Juzwenko (Ûzvenko 1961); Bołtarowycz (Boltarovič 1976) - przekazują je Iwanna Cerkowniak (2015) i Iryna Zbyr (2015). Wiele opracowań i antologii poszczególnych gatunków folkloru, a są one liczne w nauce ukraińskiej, korzysta z materiałów Kolberga. Wskazuje się na to, że udokumentował on wiele pieśni oraz utworów prozy nieznanych z innych zbiorów. Podkreśla się znaczenie jego zapisów muzycznych, wymagających od dokumentalisty odpowiedniego przygotowania. Ostatnio, także w związku z obchodami związanymi z 200-leciem urodzin Oskara Kolberga w roku 2014, odnotować należy książkę Zbyr ze Lwowa Oskar Kol'berg i jogo zbirnyk „Pokuttia” (2014) oraz tejże artykuły, niektóre z nich ogłoszone w wydaniu polskim (2015), a także artykuły Cerkowniak z Kijowa, opublikowane w Polsce (2015) i na Ukrainie (2017). Ta ostatnia obroniła w czerwcu 2017 roku w Instytucie Nauki o Sztuce, Folklorystyki i Etnologii im. M.T. Rylskiego Narodowej Akademii Nauk Ukrainy w Kijowie pracę kandydacką, przedstawiając rozprawę: Dorobek folklorystyczny Oskara Kolberga w kontekście ukraińsko-polskich związków kulturalnych końca XIX - pierwszym trzydziestoleciu 
XX stulecia, opartą głównie na materiale dotyczącym Łemków zgromadzonym przez Kolberga. Prace opublikowane w języku ukraińskim docierają do ukraińskiego społeczeństwa, ceniącego kulturę ludową traktowaną jako istotna część dziedzictwa narodowego, i zdolne są przyczynić się do upowszechnienia wiedzy o związkach naukowych i szerzej: kulturowych ukraińsko-polskich.

Świadomość znaczenia prac Kolberga dotyczących kultury ukraińskiej istniała w społeczeństwie i nauce polskiej od dawna. W sprawozdaniu z uroczystości 50-lecia jego pracy naukowej, zorganizowanej w Krakowie w roku 1889, nazwany został „badaczem ludu polskiego i ruskiego” (Turkawski 1889). Wyrazem tej świadomości było także wydanie, już po śmierci Kolberga, trzech tomów: Chełmskie, cz. 2 (1891) i Przemyskie (1891), opracowanych przez Izydora Kopernickiego, oraz Wołyń (1907), sporządzonego przez J. Tretiaka. Zainteresowanie materiałami ukraińskimi Kolberga w nauce polskiej związane było przede wszystkim z uwagą skierowaną na postać badacza. Wydano i przygotowano do wydania w „Dziełach wszystkich" tomy monografii regionalnych z tymi materiałami oraz suplementy do tomów uprzednio opublikowanych. Sięganie przez Kolberga do prac folklorystów i etnografów ukraińskich oraz kontakty z nimi, szczególnie te wywołane recenzjami Neymanna i Franka, przedstawiła opracowująca materiały Kolbergowskie Agata Skrukwa (2008). Niezależnie od prac Redakcji Dzieł Wszystkich/ Instytutu im. Oskara Kolberga, ale na podstawie opublikowanych przez tę instytucję materiałów, stosunkiem Kolberga do Rusinów i znaczeniem zgromadzonej przez niego dokumentacji ich kultury zajął się Władysław A. Serczyk (1974).

Badania nad spuścizną Kolberga pozwalają zrozumieć przeszłość. Zintensyfikowane ogłoszeniem przez Sejm Rzeczypospolitej roku 2014 „Rokiem Kolberga", należą nie tylko do etnografii historycznej, ale ważne są również dla studiów nad współczesnością. Pozwalają poznać mechanizmy przekształcania dóbr kulturowych z przeszłości w dziedzictwo i jego znaczenie dla współczesnej kultury i kształtowania tożsamości jej uczestników. Uprawiane w nauce polskiej i ukraińskiej ujawniają bliskość kulturową nabytą w trakcie wspólnego, trudnego bytowania i uświadamiają korzyści wynikające ze współpracy naukowej i w innych dziedzinach życia społecznego.

\section{Bibliografia}

Boltarovič Z.Ê.

1976 Ukrä̈na $v$ doslidžennâh pol's'kih etnografiv XIX st., Kiïv.

Cerkowniak I.

2015 Dziedzictwo folklorystyczne Oskara Kolberga w pracach ukraińskich badaczy, w: E. Antyborzec (red.), Ja daję materiał właśnie... O dziele Oskara Kolberga w dwusetna rocznice Jego urodzin, Poznań, s. 447-452.

2017 Evolûciâ poglâdiv Ivana Franka na ukraïnoznavči praci Oskara Kol'berga, w: Zbirnik Kiüvs'ki polonistični studiï, t. XXIX, s. 517-521. 
Gogol M.

2002 Taras Bulba, przeł., wstępem i przypisami opatrzył A. Ziemny, posłowie J. Tazbir, Warszawa.

Gruševs'kij M.

1922 Istoriâ Ukraïni - Rusi, t. VIII, č. II, Kiïv-Viden'.

Jasiewicz Z.

2017 Pieśń i gra obrzędowa „Zelman” u Oskara Kolberga i innych. Materiały i interpretacje, „Lud”, t. 101, s. 279-304.

Kolberg O.

1962, 1865 Sandomierskie, Warszawa. Reedycja fotooffsetowa: PTL, Wrocław-Poznań, „Dzieła wszystkie”, t. 2.

1962, 1889 Pokucie. Obraz etnograficzny, cz. 4, Kraków. Reedycja fotooffsetowa: PTL, Wrocław-Poznań, „Dzieła wszystkie”, t. 32.

1963, 1883 Pokucie. Obraz etnograficzny, cz. 2, Kraków. Reedycja fotooffsetowa: PTL, Wrocław-Poznań, „Dzieła wszystkie”, t. 30.

1964, 1890 Chełmskie, cz. 1. Reedycja fotooffsetowa: PTL, Wrocław-Poznań, „Dzieła wszystkie", t. 33.

1964, 1907 Wołyń. Obrzędy, melodie, pieśni, wydał J. Tretiak przy współudziale S. Fischera i F. Szopskiego, Kraków. Reedycja fotooffsetowa: PTL, Wrocław-Poznań, „Dzieła wszystkie", t. 36.

1966 Korespondencja, cz. 2, zebrała i opracowała M. Turczynowiczowa, red. A. Skrukwa i E. Krzyżaniak-Millerowa, PTL, Wrocław-Poznań, „Dzieła wszystkie”, t. 65.

1968 Białoruś - Polesie, z rękopisów oprac. S. Kasperczak, A. Pawlak, red. A. Skrukwa, PTL, Wrocław-Poznań, „Dzieła wszystkie”, t. 52.

1969 Korespondencja, cz. 3, zebrała i opracowała M. Turczynowiczowa, red. A. Skrukwa,

E. Krzyżaniak-Millerowa, PTL, Wrocław-Poznań, „Dzieła wszystkie”, t. 66.

1970 Ruś Karpacka, cz. 1, z rękopisów oprac. A. Demartin, B. Linette, M. Tarko, red. M. Tarko, PTL, Wrocław-Poznań, „Dzieła wszystkie”, t. 54.

1971 Studia, rozprawy, artykuły, opracowały i zredagowały E. Miller, A. Skrukwa, PTL, Wrocław-Poznań, „Dzieła wszystkie”, t. 63.

1972 Sanockie - Krośnieńskie, cz. 2, z rękopisów oprac. B. Linette, T. Skulina, red. A. Skrukwa, PTL, Wrocław-Poznań, „Dzieła wszystkie”, t. 50.

1976 Ruś Czerwona, cz. I, z rękopisów oprac. W. Kuraszkiewicz, B. Linette, M. Tarko, red.

M. Tarko, PTL, Wrocław-Poznań, „Dzieła wszystkie”, t. 56.

1978 Ruś Czerwona, cz. 2, z. 1, z rękopisów opracowali W. Kuraszkiewicz, B. Linette,

M. Tarko, red. M. Tarko, PTL, Wrocław-Poznań, „Dzieła wszystkie”, t. 57/1.

1979 Ruś Czerwona, cz. 2, z. 2, z rękopisów opracowali W. Kuraszkiewicz, B. Linette,

M. Tarko, red. M. Tarko, PTL, Wrocław-Poznań, „Dzieła wszystkie”, t. 57/2.

2002 Wołyń. Suplement do tomu 36, z rękopisów i ze źródeł drukowanych zebrała i opracowała A. Skrukwa, opracowanie muzykologiczne A. Ruda, Instytut im. Oskara Kolberga, Poznań, „Dzieła wszystkie”, t. 84.

2008 Pokucie - Suplement do t. 29-32, oprac. A. Skrukwa, A. Kustra, Instytut im. Oskara

Kolberga, Poznań, „Dzieła wszystkie”, t. 81.

Serczyk W. A.

1974 Tzw. „Ziemie ruskie” w działalności badawczej Oskara Kolberga, „Prace Etnograficzne”, z. 7, „Zeszyty Naukowe Uniwersytetu Jagiellońskiego”, t. CCCLXXV, Kraków, s. 21-33. 
Skrukwa A.

2008 „Pokucie” Oskara Kolberga, w: Oskar Kolberg, Pokucie. Suplement do tomów 2932, „Dzieła wszystkie”, t. 81, Poznań, s. V-LXI.

Świątek A.

2014 Gente Rutheni, natione Poloni. Z dziejów Rusinów narodowości polskiej w Galicji, Kraków.

Tokarska-Bakir J.

2004a Rzeczy mgliste. Eseje i źródła, Sejny 2004.

2004b Żydzi u Kolberga, w: J. Tokarska-Bakir, Rzeczy mgliste. Eseje i studia, Wydawnictwo „Pogranicze”, Sejny, s. 49-72.

Tretiak J. 1964, 1907 Od wydawcy, w: O. Kolberg, Wołyń. Obrzędy, melodie, pieśni, wydał J. Tretiak przy współudziale S. Fischera i F. Szopskiego, Kraków. Reedycja fotooffsetowa: PTL, Wrocław-Poznań, „Dzieła wszystkie”, t. 36.

Turkawski M.

1880 Wystawa etnograficzna Pokucia w Kołomyi, Kraków.

1889 Uczczenie zasług Oskara Kolberga, znakomitego badacza ludu polskiego i ruskiego, zbieracza jego podań i pieśni. Na pamiątkę dla uczestniczących w hołdzie publicznym... w Krakowie 31 maja 1989 r., wydał członek Krakowskiego Towarzystwa „Oświaty Ludowej”, Kraków.

Ûzvenko V.A.

1961 Ukraïns'ka narodna poetična tvorčist' u pol'skij fol'kloristici XIX st., Kiï. Zbyr I.

2014 Oskar Kol'berg i jogo zbirnik „Pokuttâ”, L’viv.

2015 Wkład Oskara Kolberga w rozwój ukraińskiej folklorystyki końca XIX i poczatku XX wieku (na podstawie jego zbioru „Pokucie”, w: E. Antyborzec (red.), Ja daję właśnie materiał... O dziele Oskara Kolberga $w$ dwusetna rocznicę Jego urodzin, Poznań, s. $433-446$. 